\title{
Os estudantes: dentro e fora da escola
}

\author{
María Teresa Quiroz Velasco \\ Doutora em Sociologia pela Universidad Nacional Mayor de San Marcos e mestre em \\ Sociologia pela Pontifícia Universidade Católica do Peru. Professora sênior de Comunicação da \\ Universidad de Lima e diretora do Instituto de Investigação Científica da mesma instituição. \\ É membro do Conselho Diretivo da Federação Latinoamericana de Associações de Faculdades de \\ Comunicação (FELAFACS), que presidiu em 2003 e 2009. \\ E-mail: tquiroz@ulima.edu.pe
}

Resumo: Como parte de uma pesquisa em curso na Faculdade de Comunicação da Universidade de Lima', antecipo alguns resultados que podem ser úteis para entender o abismo existente entre o que acontece dentro e fora da escola em relação aos processos de aprendizagem e a tecnologia. É fato que as experiências dos mais jovens, seus interesses e motivações em torno da internet e das redes sociais estão baseados na comunicação e no entretenimento.

Palavras-chave: Aprendizagem, tecnologia, escola, comunicação, internet.
Abstract: The author brings some results of part of a research running up in Faculdade de Comunicação of Universidade de Lima. They can be utile to understand the abysm between what happens inside and outside school in the aspect of learning and technology processes. It is a fact that the youngs' experiences, their interests and motivations around Internet and social networks are based on communication and entertainment.

Keywords: Learning, technology, education, communication, internet.

É notória a vantagem dos estudantes que têm uma conexão rápida e de qualidade com a internet em casa. Podem acessar a rede com maior frequência, experimentar, inovar e tornar-se independentes quanto às exigências escolares. Cria-se, por esta razão, um abismo adicional, no aspecto digital, quanto ao que ocorre dentro e fora da escola, bem como entre aqueles que têm internet em casa e os que não têm e recorrem, em horários preestabelecidos, e mais curtos, aos acessos públicos.

No Peru tem ocorrido um crescimento do acesso e do consumo de internet dentro de casa, sem desmerecer os esforços das escolas públicas e privadas com menos recursos, orientados a dotar de uma infraestrutura tecnológica básica os seus centros educacionais, capacitar tecnicamente seus professores e oferecer conhecimentos básicos em tecnologia para seus alunos. Lamentavelmente, ainda se ignora que o problema não é apenas técnico, mas passa pela construção de espaços adequados de comunicação e aprendizagem. Seria preciso formar professores no debate amplo, reorganizar as diretrizes curriculares e organizá-las a partir das mudanças nos processos educacionais centrados na aprendizagem colaborativa e na participação dos alunos. Estes, guiados adequadamente, podem

Recebido: 17.06 .2010

Aprovado: 23.11.2010

1. Pesquisa realizada como parte do ano sabático na Universidade de Lima, intitulada: "Comunicação e aprendizagem. Os estudantes e as redes sociais". 
2. BUCKINGHAM, D. Más allá de la tecnología. Aprendizaje infantil en la era de la cultura digital [Além da tecnologia. Aprendizagem infantil na era da cultura digital]. Buenos Aires: Manantial, 2008. p. 129 se comunicar e compartilhar conhecimentos com os colegas na própria escola, e com outros em qualquer lugar do país ou do mundo.

Diante das limitações das escolas, os jovens preferem - se tiverem a infraestrutura adequada - o espaço da casa, porque há menos restrições, sentem-se mais livres e podem satisfazer seus interesses e motivações. Isto significa admitir, mais uma vez, que a educação continua atrasada e caminha bem lentamente diante das transformações e inovações da vida social. E também admitir a reduzida capacidade que tem a escola em incorporar a realidade, o país e o mundo, e atender aos verdadeiros interesses dos jovens, cujas experiências sociais e culturais são, efetivamente, outras:

Mas este novo "abismo digital" no uso das tecnologias dentro e fora das escolas também poderia ser interpretado como um sintoma de um fenômeno muito mais geral: a existência de uma distância cada dia maior entre os "mundos vitais" cotidianos das crianças fora da escola e o que é privilegiado por muitos sistemas educacionais ${ }^{2}$.

Já faz décadas que a socialização das crianças e adolescentes não passa somente pela instituição escolar e que os próprios valores que a escola encarna, relacionados à ordem, à disciplina e à adaptação aos modelos dominantes, estão em crise. A educação é importante para as crianças, a escola é um espaço significativo, mas não é único, nem o único. O discurso do dever ser sobre seu futuro, sobre suas relações, sobre o sexo, é tangencial. Hoje em dia as informações encontram-se na internet e nos espaços e redes sociais nos quais se compartilham experiências e procuram-se respostas diretamente e por eles mesmos, sem a mediação das autoridades paterna, materna ou do professor.

Não é necessariamente um espaço caótico este que as crianças e adolescentes constroem, como muitos poderiam pensar. Através da tentativa e do erro experimentam, jogam videogame e planejam estratégias, bem como vão adquirindo habilidades e conhecimentos. Tudo isso não é, entretanto, matéria de um curso ou disciplina, e sim o que adquirem na prática, nas relações sociais, interagindo com os demais e participando em comunidades de usuários, experimentando, e tudo isso sem receber instruções. Respondem adequadamente aos pais ou adultos e ensinam o que sabem. Mas, além disso, vão se constituindo como sujeitos culturais, definindo seus interesses, objetivos, planos e sua própria identidade.

Buckingham se pergunta sobre o que deve ser feito para vencer o abismo digital entre a escola e o mundo extraescolar. Ele responde, indicando o seguinte:

a escola deve enfatizar o desenvolvimento das atividades críticas e criativas das crianças em relação aos novos meios para que a "alfabetização nos novos meios" deva constituir-se como um direito educacional básico (...) Não é possível compreender de modo cabal os meios digitais, se insistirmos em considerá-los simplesmente uma questão de máquinas e técnicas de hardware e software. A internet, os videogames, o vídeo digital, os telefones celulares e outras tecnologias contemporâneas oferecem novas maneiras de mediar e representar o mundo, bem como novas formas de se comunicar. Fora da escola, as crianças estão se relacionando 
com estes meios não como tecnologias, e sim como formas culturais. O problema trazido pela maioria dos usos educacionais destes meios é que eles continuam sendo considerados meros meios instrumentais para difusão de informação, como se fossem ferramentas neutras ou materiais de ensino ${ }^{3}$.

Ele acrescenta que a educação na escola precisa incorporar os meios para evitar o imenso abismo entre o discurso escolar e a aprendizagem prática que os mais jovens adquirem por outras vias. Daí a necessidade que os jovens têm de se expressar por conta própria, de produzir suas próprias formas de comunicação e deixar de serem receptores passivos de conteúdos.

A questão da relação entre tecnologia e educação na escola, bem como em casa, é parte dos debates nos meios escolares, universitários, nos meios de comunicação em massa, nos debates internacionais, no mundo empresarial. $\mathrm{O}$ que se alcançou? Nossas crianças e adolescentes aprendem mais e melhor? Ainda não há respostas conclusivas. Não obstante, e apesar de umas e outras asseverações, o lugar dos meios digitais na vida dos mais jovens é definitivo e tende a crescer. Não deixa de ser fundamental o peso do capital cultural de tais estudantes, o qual influi no maior ou menor aproveitamento educacional. Ou seja, estamos diante de múltiplos abismos: um socioeconômico e cultural, outro entre a cultura e a escola, outro entre a cultura da escola e a cultura extraescolar.

Dentro das abundantes perguntas, é central este questionamento: o que a escola deve oferecer, se os estudantes são cada vez mais independentes em seus processos de aprendizagem? Nem a escola como tal, nem os professores e pais podem, nem devem, pretender competir com as fontes de informação de que os mais jovens dispõem.

O papel dos professores no processo de aprendizagem é analisado pelo linguista peruano Eduardo Zapata, em um artigo no qual reflete sobre o novo paradigma da educação, e propõe que o professor se aproxime de outro modo do aluno, ganhando lugar, mais além da autoridade que representa, e muito mais por sua capacidade de se vincular a um educando que não é mais o mesmo de antes. Sustenta que a eletrotonalidade torna os jovens mais hábeis na operação de vários códigos de forma simultânea, os torna multissensoriais e não somente visuais, e os tornou filhos de uma cultura que os distingue da homogeneidade e estabilidade, deixando-os pragmáticos, ativos e criativos: “(...) a eletrônica destronou o professor de seu papel excludente de divindade, pai ou autoridade hereditários. Tudo isso - graças à tecnologia - o professor deve conquistar na sala de aula. Com rigor, mas com carinho e respeito aos estudantes"^.

\section{RESULTADOS DA PESQUISA. OLHAR DOS ESTUDANTES}

A pesquisa intitulada Comunicação e aprendizagem. Os estudantes e as redes sociais efetuou um estudo qualitativo entre pais e estudantes no ano de 2009, sendo que estes últimos em grupos focais, com adolescentes entre 14 e 16 anos. Participaram um total 25 homens e 29 mulheres, num total de 9 focos: três de
3. Ibid., p. 153.

4. Zapata, E. Al Alumno con cariño [Ao aluno, com carinho]. Peru: El Comercio. Opinión. 5 set. 2009. p. 9. 
nível socioeconômico médio/alto, três de nível socioeconômico médio/baixo e 3 de nível socioeconômico baixo/muito baixo. Tomaram parte estudantes de diversos centros escolares. Dada a limitação de espaço, mencionarei os resultados referentes aos jovens adolescentes.

Eles se comunicam de diversas maneiras com seus pares. $\mathrm{O}$ uso da internet - celular, MSN, Hi5, Facebook, entre outros - introduz novos elementos nas formas conhecidas do encontro pessoal e em grupo. As ferramentas e os novos espaços de comunicação permitem aumentar o número de amigos com os quais se comunicar. Seu campo de socialização através da rede cresce e se amplia porque podem entrar em contato com pessoas próximas e distantes, conhecidas e desconhecidas, de outras escolas, de qualquer parte do país ou mesmo do mundo. Os amigos ou conhecidos não provêm somente de encontros presenciais, mas também de interações na rede. Ainda assim, apesar de suas relações sociais através do computador serem abundantes, tendem também a ser mais efêmeras, esporádicas, com menos compromisso com o outro, porque seus contatos são mais imediatos, instantâneos, sem horários específicos, particularmente fora do espaço escolar, durante seu tempo livre. Quer dizer, a vida social dos mais jovens transita por muitas vias, para além do espaço escolar.

Apesar do computador e do celular serem os intermediários por excelência para coordenar reuniões, encontros a distância, a presença física continua sendo importante. Quando estabelecem uma relação mais profunda ou duradoura, preferem o contato interpessoal para se comunicar.

Os jovens realizam várias atividades ao mesmo tempo. Aqueles que têm computador em casa assistem à televisão com o computador ligado, conversam com a família enquanto falam pelo chat ou fazem as tarefas da escola, baixam músicas enquanto conversam, fazem tarefas ou leem mensagens. A tela do computador é um espaço que permite a convivência de diversas atividades, das quais o centro é o usuário, que define suas preferências, prioridades ou interesses.

Utilizam escrita abreviada, isto é, novas linguagens híbridas, ao se comunicarem através das mensagens de texto. Abreviam as palavras com uma finalidade prática: economizar tempo e espaço sem perder a o sentido do que é falado. O imediatismo, a interatividade e a economia de esforço explicam esta linguagem comum. Costumam compartilhar uma série de termos, compreendidos pelos pares, mas não necessariamente pelos adultos. Não consideram esta linguagem abreviada como um gíria, e sim como um modo de se expressar com maior rapidez pelo MSN ou por outros canais. Trasladam estas formas de comunicação ao âmbito escolar, e são criticados pelos professores por não respeitarem a pontuação nem a acentuação das palavras.

Os adolescentes se iniciaram desde bem jovens no consumo da televisão e nos chamados meios tradicionais, como também nos digitais. Estão habituados a interagir na rede, simultaneamente com outros, e se definem por estarem em comunicação com um número crescente de pares. Transitaram de seu vínculo com a televisão, externo e certamente passivo, para outro no qual cada um deles é o centro das comunicações que estabelecem com muitos. Os novos 
meios passaram a se somar, cada vez de forma mais intensa, ao consumo dos tradicionais meios de comunicação. Incidem no uso diverso dos recursos com os quais contam os adolescentes em casa, as atitudes e o valor atribuído pelos pais, bem como seu contexto educacional.

A internet é mais que uma ferramenta, é um espaço de comunicação bastante valorizado, faz parte da vida dos mais jovens, e ali se produzem suas relações, encontros e buscas. Enquanto para os adultos, professores e pais, a internet faz parte de um novo espaço ao qual têm que se adaptar, para os adolescentes é parte natural de sua existência. Oferece a eles uma possibilidade a mais de conversar com amigos e de estar em contato permanente, é um dos aspectos com os quais mais se divertem e, além do mais, é bastante útil por sua praticidade e imediatismo.

Vale dizer que há um aumento no uso da internet para a informação, especialmente entre os estudantes de 12 a 17 anos, porque as escolas estão cada vez mais equipadas e buscam integrar tecnologia e informação. Os alunos são incumbidos de fazer pesquisas ou buscas através da internet. Ela se transformou em uma das principais fontes de informação dos adolescentes, à qual sempre recorrem em primeiro lugar. Sem dúvida, ao fazer as tarefas com a internet, não as realizam de forma exclusiva, mas ao mesmo tempo abrem páginas de chat e entretenimento.

O acesso aos meios tecnológicos e as atitudes da família, tanto do pai quanto da mãe, vêm mudando aceleradamente. Isto é, por causa do impacto público que tem a questão, o uso que lhe é dado na escola e de sua própria experiência no trabalho, os pais estão cada vez mais interessados e preocupados que seus filhos se familiarizem com a tecnologia. Não deixam de existir temores e resistências, especialmente pelos riscos que implica o vínculo com estranhos e pelas imagens perigosas e a pornografia. Em geral, seria possível qualificar como relativamente flexível a atitude dos pais diante da tecnologia que seus filhos utilizam. É possível encontrar as diferenças nas formas de controle que se pode notar. Os adolescentes homens têm maior liberdade e autonomia quando usam a internet, tanto dentro de casa quanto fora dela. Os pais que provêm de setores socioeconômicos mais altos são cada vez mais abertos a este uso, inclusive o estimulam e facilitam o acesso ilimitado, por estarem suas casas conectadas à internet durante todo o dia. No caso do celular, fiscalizam os gastos, especialmente as mães. Os pais com menos recursos econômicos e educacionais se mostram mais temerosos e cautelosos em relação ao acesso mencionado, têm certos preconceitos acerca dos efeitos negativos da internet, especialmente no caso das mulheres, às quais notam ficar mais expostas ao contato com pessoas que poderiam não ter boas intenções nas lan houses.

A possibilidade de fazer amigos através da rede permite aos jovens conhecer pessoas bastante diversas, que provêm não apenas do colégio ou do próprio bairro, mas de outros centros educacionais ou distritos e até do estrangeiro. Têm a possibilidade de ampliar seu circuito de comunicação via internet com pessoas que vivem em lugares mais distantes. Não obstante, é preciso destacar 
comunicação \& educação • Ano XVI • número 2 • jul/dez 2011

que os adolescentes controlam os amigos que lhes interessam na rede. Existem diferenças significativas por sexo. Para as mulheres, o valor de estarem disponíveis para conversar, trocar fotografias, conversar pelo chat é bem maior que para os homens, sem distinção de origem social. A média de contatos, no caso dos homens, é menor que das mulheres. A conversa ou o diálogo entre os homens gira em torno dos jogos em rede e das conversas sobre festas, sexo e futebol. Os espaços em que se comunicam diferem por setores socioeconômicos, e se produzem através de casa e em outros casos em lan houses. O esporte é outro dos temas que está bastante presente em suas relações de amizade.

Como se vem sustentando, nos circuitos de comunicação na rede, se reproduzem os espaços e diferenças sociais que existem no mundo real. Enquanto as crianças e adolescentes dos setores médios e altos são bastante fechados, seletivos, e se entrincheiram para defender seus grupos, outros, como os de origem média a baixa, encontram nestas redes a oportunidade de conversar com pessoas desconhecidas e ampliar seus grupos de amigos.

Estes dados nos permitem apreciar que há dois mundos de aprendizagem, ou, talvez, que a escola perdeu a hegemonia e a centralidade na transmissão de conhecimentos e aprendizagem. Hoje ela possui o grande desafio de integrar os processos, diante do risco de ficar fora do interesse dos mais jovens. A escola pode e requer não apenas se transformar no espaço de aprendizagem através do qual os distintos referentes passam, como também desenvolver as competências necessárias para que os alunos e seus professores interajam com o mundo real para continuar aprendendo.

\section{REFERÊNCIAS BIBLIOGRÁFICAS}

BUCKINGHAM, D. Más allá de la tecnología. Aprendizaje infantil en la era de la cultura digital [Além da tecnologia. Aprendizagem infantil na era da cultura digital]. Buenos Aires: Manantial, 2008.

ZAPATA, E. Al Alumno con cariño [Ao aluno, com carinho]. Peru: El Comercio. Opinión. 5 set. 2009. 